ISSN 2392-4896 (online)

ISSN 2392-4888 (print)

Journal of Management and Development Studies Vol. 26:pp.79-91

Available online http://nasc.org.np

(C2015 Nepal Administrative Staff College

\title{
Maternal Health Care Service Utilization and Its Role in Postpartum Family Planning Use in Nepal
}

Komal Prasad Dulal

Assistant Professor at Centre for Population and Development (CPAD), Purbanchal University, Nepal

Email: komal.dulal@gmail.com

Accepted 10 August 2015

Family planning and maternal health care programme has been initiated in an integrated approach for a long time in Nepal. However, the use status of family planning method could not be presented at good instance. The International Conference on Population and Development (ICPD), 1994 and later millennium development goal 2002, both paved the way out for the situation mostly in the developing countries. Nepal also has made some changes in its services aiming to reduce high maternal mortality and promote to use family planning method. Use of family planning method within 12 months after childbirth could be a right solution for many developing countries like Nepal having high unintended birth. Therefore, this paper aims to analyse the role of maternal health care service utilization in initiating use of family planning method after post-partum period. Women's data file from Nepal Demographic Health Survey, 2011 has been used for the analysis. Bivariate and multivariate analysis result have revealed that the role of delivery care, controlling other variables seems to be much appreciable in getting family planning use within 12 months of delivery. Effects of some study variables besides delivery care remains unchanged in different models. Therefore, embracing family planning programme along with maternity care components would have implications towards - increasing current use of family planning, reducing the chances of unwanted/unintended birth, providing opportunities to control over female own body, contribution in achieving replacement level fertility and maintaining good health for both mother and the baby.

Key words: maternal health, post-partum family planning, delivery care

\section{Introduction}

In a view to integrate family planning as an integral part of maternal health care services, government of Nepal introduced family planning and maternal and child health care component from its Third five year plan (NPC, 1963).Despite commitments made during each plan period, the maternal health care service utilization before 1990 in Nepal was not so much substantial due to the lack of health facilities in the rural areas of Nepal. The data on maternal mortality itself reveals that the situation of Nepal was worse till mid-1990s. The International Conference on Population and Development (ICPD), 1994and later millennium development goal 2002, 
both paved the way out for the situation mostly in the developing countries. Nepal also made some changes in its services aiming to reduce high maternal mortality.

Nepal Demographic Health Survey (NDHS), 2011 revealed that the maternal health care components have been improved since 2001. About 85 per cent of the pregnant women received at least one time Antenatal Care (ANC) visit which has jumped from 74 per cent of 2001(MoH et.al. 2001; MoHP et. al. 2012). Similarly, women prefer to utilize maximum institutional delivery as far their capacity favours. Currently, about 39 per cent women give birth to child at health facility which was only 10 per cent in 2001 . Similarly, about 45 per cent of women go for post-natal care (PNC) check-up within six weeks of delivery that is considered as most crucial time for both mother and the baby to get information on various health issues. The PNC check-up is very important for the country like Nepal where 45 percent of births still take place with the presence of relatives/friends, considered as unsafe in medical environs. The Government of Nepal has emphasized on post-partum family planning (PPFP) counselling to the women who utilize PNC (MOHP et. al., 2012; DoHS, 2014). A woman who comes for the utilization of any component of maternal health care services routinely will get an opportunity to interact not only with the health personnel but many other people who might have reached health institution for utilization of family planning services.

This context generates two pathways. First, a woman learns to take care of her own health and growing foetus until she gives birth to child. This will help to escape the existing barriers to use health services. Second, after a long exposure to health services, interaction with service provider and the persons gathered for health seeking; a woman gains enough knowledge and timing to start family planning method soon after delivery. This is the main pathways through which one can get information to stop child bearing. Therefore, it is considered here that utilization of maternal health care component can play a vital role in disseminating as well as encouraging the use of family planning method within a year of delivery.

This study is primarily concentrated to observe when a non-amenorrhoeic woman would start using family planning method after the last childbirth. But, this study also includes those women who would like to give birth to a child before 24 months of the last child. The post-partum family planning(PPFP) is not only concentrated to start family planning soon after delivery but also aims to maintain 24 months gap between two children which is considered as the proper health benefit for both mother and child. Timing to use family planning after childbirth is most crucial to reduce unintended births because still about 30 percent last births are unintended and this result has not been so much improved since 2001 in Nepal. While looked into the birth spacing, still 50 percent of women have maintained spacing less than 36 months. Similarly, about 21 percent have birth spacing less than 24 months (MOHP et.al. 2012).In such a situation, if all the births in the days to come will concentrate with at least of 24 months spacing, the majority of maternal and child death could reduce at large except some undeniable death in medical science. Such spacing is also essential for good maintenance of health of women due to heavy loss of vitamins after childbirth or breastfeeding.

It is considered in this study that the components of maternal health care (ANC, DC and PNC) could play decisive role to start using family planning method within a year after childbirth, soon after menstruation cycle resumes. Since the Government of Nepal has emphasized on PPFP counselling as a component of maternity care, to observe the impact one has to observe when the women have started PPFP.A study of this kind also fulfils the literature 
gap in family planning research. Expecting that menstruation cycle resumes within a year of childbirth to all women who have given the last birth five year preceding the survey, the present study on timing of PPFP use has been examined. Therefore, the study on timing of initiating use of family planning after the last birth is imperative for developing countries like Nepal which has been struggling for aforementioned situation since a long time to make more intervention in this area in the days to come.

Determinants of modern contraceptive use are usually examined in isolation of the effect of exposure to other aspects of health care systems. Women's interaction with organised health service system during post-conception and postpartum stages of reproduction can provide an opportunity to channelize contraceptive services information and counselling. A study by Zerai and Tsui (2001) shows that after controlling for effects of living in high health service contact areas and with various demographic and background factors, prior use of prenatal care has a strong influence on subsequent use of modern contraception in Bolivia, Egypt and Thailand. A study before this kind of study by using 1992 DHS data from Morocco finds that women who more intensely use maternal and child health $(\mathrm{MCH})$ services are more prospective to use modern contraceptive services subsequently (Hotchkiss et al. 1999). Similarly, a study based on DHS of Kenya (2008-09) and Zambia (2007) shows that the intensity of ANC and PNC service use and postpartum modern contraceptive practice were not influenced by common unobserved factors. Cox proportional hazard models show significant associations between the service intensity of ANC and PNC, as well as ANC only, and postpartum modern contraceptive use in both countries. However, no significant association was observed between PNC service intensity and postpartum family planning practice. It further indicates the use of ANC and service after childbirth would be a window of opportunity to promote the use of modern contraceptives (Do \&Hotchkiss, 2011).

Ahmed and Mosley (2002) conclude that the use of contraceptives and $\mathrm{MCH}$ care are significantly associated and are independent of intervening factors. They argue that families develop a joint demand for better-quality health and limited family size and translate these demands into action by using health services for mothers and for children and also by voluntarily regulating fertility which ultimately saves unusual death of mother during pregnancy and childbirth. How a woman who goes for health care at maternity situation learns on family planning use as spelled by behavioural scientists is that the adoption of a new behaviour is a process that involves passage through a sequence of behavioural changes that begins with awareness, extends through accumulation of knowledge, and ends in behavioural consolidation. According to these hierarchical behavioural models, McGuire (1981) urges that the consolidation of one behaviour (e.g., the adoption and use of contraceptives) may facilitate more rapid adoption of a similar behaviour (e.g., the use of health care services, or vice versa).

Hotchkiss et al. (2005), on relationship between $\mathrm{MCH}$ service utilization and contraceptive use in five countries: Bolivia, Guatemala, Indonesia, Morocco, and Tanzania, reveal that the intensity of $\mathrm{MCH}$ service use is positively associated with subsequent contraceptive use among women. This finding further suggests that increasing investments in programmes that are effective in improving the use of $\mathrm{MCH}$ services can also be a viable strategy to improve use of modern family planning techniques. Another important case is the unwanted pregnancies which can offer useful perspectives on the need to improve and expand the range of family planning options available to women in developing countries. A woman 
having pregnancy with wanted births exert a significant influence on health care use in Thailand after controlling for other determinants of maternal health care utilization. Women with unwanted pregnancies are less likely to seek prenatal care or receive tetanus toxide inoculations. In addition, women from disadvantaged socioeconomic groups, women with high parity and those with lower educational levels have the highest proportion of unintended pregnancies.

The health care utilization undergoes unutilized and subsequently this may result in the disuse of family planning method (Raghupathy, 1997). But, how can one determine the use of family planning method could be another important issue. Yahaya (2002) claims social characteristics such as marital status, religion, marital position and seclusion status determine the use of family planning devices. Why a woman do not use family planning to stop further degradation of reproductive health in such a high maternal mortality situation of the country can be determined by the women's social characteristics. Therefore, it can be said that not only by providing family planning method to all women of reproductive health in isolated situation can support to woman. Instead of this, there should be the recognition of social characteristics and the programme should proceed to overcome the situation to lower the fertility and to provide safe motherhood to all women.

\section{Policy and programme on family planning and maternal health: Post-1990s}

Nepal Safe Motherhood Policy 1998 stressed on the use of ANC, institutional delivery supported by skilled births attendants and use of PNC in a view to save women from all kinds of maternal complications and deaths. Use of 2 TT inoculation, use of Iron/Folic tablets, deworming tablets during pregnancies, birth under the supervision of skilled attendants and proper care of women after childbirths were the major programme that are being implemented intensively since 1990s under the international standards and norms recommended by World Health Organization. Government of Nepal has brought many changes since 1990 in its policy and programme. One important activity which comes under the safe motherhood programme is AAMA Programme. Transportation allowances programme initiated in 2005 to support pregnant women to deliver at health institution (DoHS, 2005) and institutional delivery and the necessary medicines used during the child births are made free of cost since 2009(DoHS, 2009) are the major inputs under the AAMA Programme. Besides that, consistent efforts of Government of Nepal towards improving mother and the neo-natal health have been revised and the revised safe motherhood and Neonatal Health Long Term Plan (SMNHLTP 20062017) includes skilled attendants, safe abortion, equity and access efforts, among others, under safe motherhood umbrella (DoHS, 2014).

On the other hand, to improve the health status of mothers and children and overall quality of life of the whole family by increasing access and utilization of quality family planning services is the main objective of National Family planning programme of Nepal. It infers family planning is the Government's most prioritised programme under Nepal Health Sector Program II (2010-2015). Effective integration of family planning services with other health services under the regular programme through Department of Health Services and its institutions was arranged up to grassroots level (DoHS, 2014). 
Maternal Health Care Service Utilization and Its Role in Postpartum Family Planning Use in Nepal

\section{Data and methods}

This paper is based on Nepal Demographic Health Survey 2011 women's data file. A total of 12,674 women of reproductive age (15-49 years) were interviewed during the survey. Out of them, only 4,148 married women in the age group 15-49 had given birth to the most recent child in the five years preceding the survey. Out of 4,148 women, this paper relies on the information of women who were non-amenorrheic during the period, therefore, reducing the sample to 3,371. Further, this paper is primarily concentrated to examine the role of maternity care components on the timing of use of family planning method soon after the birth of last child during the five years period; the final sample becomes 1,556 women who have used postpartum family planning methods.

\section{Dependent variable}

The dependent variable of this study is the timing for the use of modern contraceptive method after the last childbirth. This is obtained by computing the Century Month Code (CMC) of contraceptive use and the birth of most recent child in the five year preceding the survey from Nepal Demographic Health Survey 2011 by excluding non-amenorrheic women and the women who were already declared as an infertile. The outcome of this computation measured in months is further categorised dichotomous as - used FP within a year of recent child birth and After 12 months.

\section{Independent variables}

The independent variablesare three components of maternal health care services-ANC, delivery care (DC) and PNC. Delivery care is categorised into two categories: a. Last birth given at health facility $b$. Last birth given without health facility. Here, health facilities cover public and non-governmental institutions. PNC is also made here dichotomous as service received within six weeks of delivery and beyond the stipulated time. However, ANC includes the number of visits during the last childbirth, ANC visit made in each trimester, iron/folic tablet taken, TT inoculation taken during pregnancy, informed about the pregnancy complication during the last visit, blood pressure measured, blood sampled measured and urine sample measured.

In the variable coding, higher score means better performance. Instead of treating all care comprised in ANC composite index equally,the weights for the different cares are assigned on the basis of the available literature on the relative roles of different components in improving maternal health (Ram \& Singh, 2006). By computing all 8 variables, the value ranges from 0 to 18 . Further, the values are categorised into three groups as: $0=$ No care at all, 1 $15=$ Moderate care and the value of 16-18 (80 percent and above care) $=$ High care.

Besides these three maternal health care components, some other socio-economic and demographic variables are also taken into consideration which would also affect contraceptive use in Nepal. Women's education, husband's education level, age of women at most recent child birth, visited by Family Planning workers in the last 12 months, Heard FP on Radio/TV/Newspaper/Magazines last few months, visited by FP workers in last 12 months, visited health facility in last 12 months, information on FP received from health facility. 


\section{Construction of new variables}

Some socio-economic variables available in the data files are further reorganized. Based on the continuous data on education, it has been categorised into three as- No education, Class 1-9 and School Leaving Certificate (equivalent to class 10) and above. It has been expected that these three groups would have a differences in understanding on the use of family planning soon after childbirth. Similarly, age 20-34 is appropriate age for delivery because women may face biological complications in childbirth before 20 and after 34 years of age. Therefore, age can be a determinant for the use of family planning method. The age of women at the birth of child is categorised into three groups- less than 20 years, 20-34 years, and 35 and above. Media plays vital roles to aware people when these media covers advertisement related to FP devices and the paybacks in family life. Three variables are taken here so that the exposure on these media could have impact in use of Post-Partum Family Planning Method (PPFM). Two components of maternal health care- ANC and DC- variables are retained for the analysis as there is high correlation (more than 0.7) between DC and PNC. It is supposed that generally who go for delivery care at health institution, the counselling on use of post-partum family planning is common. After looking into association using chi-square test, a logistic regression is used to determine coefficient of the factors influencing use of post-partum family planning. Different models are constructed to see the gross and net effects of maternal health care service utilization in initiating family planning use within a year of childbirth.

\section{Results}

Results show that about 46 percent women have been using family planning method. Currently, 360 Frequency Modulation (FM) radio stations including government radio channel are functioning across Nepal (MoIC, 2012). These radio stations broadcast news and information jingle in different regional languages. As the majority of Nepali live in rural area, about 52 percent of women have heard family planning information on radio in last few months as compared to 41 percent from TV and a small proportion from print media. On the basis of government's Information Education and Communication (IEC) policy to supply information on health related message from media, radio is seen as most influential one in Nepal.

Female community health volunteers (FCHVs) who are available in all wards (lowest unit of Village Development Committee) throughout Nepal are also reliable source for providing contraceptives (condoms and pills) under public provisions. They are field level staff to assist community members in their health issues. One question related to FCHVS asked in DHS was: Whether the family planning worker visited them in the last 12 months? Only 28 percent of women replied "yes" on such visits. On the other hand, about 77 percent women had visited health facility for health purpose in the last 12 months. It confirms that 3 out of 4 women have any kinds of interaction with health professionals. It shows increasing health seeking behaviour of people. However, only about 21 percent of the women reported that they have received information from health facility. It emphasizes that an increased effort is required to disseminate health information from health facility. Further, only 10 percent women have received information on family planning at the time of PNC visit. Similarly, about 12 percent did not have any ANC visit for the last child. While, 35 per cent had higher level ANC care and 
53 percent with moderate visit. Similarly, 39 percent women had last delivery in the health institution and 45 percent received PNC, little higher than institutional delivery.

Table 1: Characteristics of women who have used post-partum family planning, Nepal 2011, $(\mathrm{N}=1556)$

\begin{tabular}{|c|c|c|c|}
\hline Variables & Response & Percent & Number \\
\hline \multirow{2}{*}{$\begin{array}{l}\text { Heard family planning on radio } \\
\text { in the last few months }\end{array}$} & No & 47.9 & 746 \\
\hline & Yes & 52.1 & 811 \\
\hline \multirow{2}{*}{$\begin{array}{l}\text { Heard family planning on TV in } \\
\text { the last few months }\end{array}$} & No & 59.4 & 925 \\
\hline & Yes & 40.6 & 631 \\
\hline \multirow{2}{*}{$\begin{array}{l}\text { Heard family planning in } \\
\text { newspaper/magazine in the last } \\
\text { few months }\end{array}$} & No & 86.5 & 1347 \\
\hline & Yes & 13.5 & 210 \\
\hline \multirow{2}{*}{$\begin{array}{l}\text { Visited by family planning } \\
\text { worker in the last } 12 \text { months }\end{array}$} & No & 72.3 & 1126 \\
\hline & Yes & 27.7 & 431 \\
\hline \multirow{2}{*}{$\begin{array}{l}\text { Visited health facility in the last } \\
12 \text { months }\end{array}$} & No & 22.7 & 354 \\
\hline & Yes & 77.3 & 1203 \\
\hline \multirow{2}{*}{$\begin{array}{l}\text { Information on family planning } \\
\text { received from health facility }\end{array}$} & No & 79.3 & 1234 \\
\hline & Yes & 20.7 & 323 \\
\hline \multirow[t]{3}{*}{ Women's education } & No Education & 41.5 & 646 \\
\hline & Class 1-9 & 40.2 & 625 \\
\hline & SLC and above & 18.3 & 285 \\
\hline \multirow[t]{3}{*}{ Husband's education } & No Education & 19.6 & 305 \\
\hline & Class 1-9 & 49.9 & 777 \\
\hline & SLC and above & 30.5 & 474 \\
\hline \multirow{3}{*}{$\begin{array}{l}\text { Age of mother at the birth of } \\
\text { most recent child }\end{array}$} & Less than 20 & 14.3 & 222 \\
\hline & $20-34$ & 78.8 & 1227 \\
\hline & 35 above & 6.9 & 107 \\
\hline \multirow{2}{*}{$\begin{array}{l}\text { Talked about family planning at } \\
\text { PNC visit }\end{array}$} & No & 90.1 & 1403 \\
\hline & Yes & 9.9 & 154 \\
\hline \multirow[t]{3}{*}{ Antenatal care } & No care & 11.7 & 182 \\
\hline & Moderate care & 52.9 & 823 \\
\hline & High Care & 35.4 & 551 \\
\hline \multirow[t]{2}{*}{ Delivery care } & Not at health facility & 60.6 & 943 \\
\hline & Health facility & 39.4 & 613 \\
\hline \multirow[t]{2}{*}{ Postnatal care } & $\begin{array}{l}\text { No care with in six } \\
\text { week }\end{array}$ & 55.5 & 864 \\
\hline & $\begin{array}{l}\text { Care with in six } \\
\text { week of delivery }\end{array}$ & 44.5 & 692 \\
\hline
\end{tabular}

\section{Differential in post-partum family planning use}

About 53 percent women who were exposed to Radio used contraceptives within 12 months of their last birth. This proportion is less as compared to TV (58 percent) and Newspaper/Magazines (65 percent). Large proportion of women who did not visit health worker started using contraceptives within 12 months of delivery. In case of women who had 
visited health facility for any reasons, about 57 percent initiated use of contraceptives in less than one year following delivery.

Table 2: Percentage distribution of women who used contraceptives within or after 12 months of delivery by background characteristics

\begin{tabular}{|c|c|c|c|c|c|}
\hline Variables & Response & $\begin{array}{c}\text { After 12 } \\
\text { Months (\%) }\end{array}$ & $\begin{array}{c}\text { Within } 12 \\
\text { months }(\%)\end{array}$ & Total & $\mathrm{X}^{2}$ value \\
\hline \multirow{2}{*}{$\begin{array}{l}\text { Heard family planning } \\
\text { methods in radio in the } \\
\text { last few months }\end{array}$} & No & 42.1 & 57.9 & 746 & \multirow[t]{2}{*}{$4.343^{*}$} \\
\hline & Yes & 47.3 & 52.7 & 811 & \\
\hline \multirow{2}{*}{$\begin{array}{l}\text { Heard family planning } \\
\text { in TV in the last few } \\
\text { months }\end{array}$} & No & 46.6 & 53.4 & 925 & \multirow[t]{2}{*}{2.989} \\
\hline & Yes & 42.2 & 57.8 & 631 & \\
\hline \multirow{2}{*}{$\begin{array}{l}\text { Heard family planning } \\
\text { in newspaper/magazine } \\
\text { in the last few months }\end{array}$} & No & 46.3 & 53.7 & 1347 & \multirow[t]{2}{*}{$8.604 * * *$} \\
\hline & Yes & 35.4 & 64.6 & 209 & \\
\hline \multirow{2}{*}{$\begin{array}{l}\text { Visited by family } \\
\text { planning workers in last } \\
12 \text { months }\end{array}$} & No & 41.5 & 58.5 & 1125 & \multirow[t]{2}{*}{$17.704 * * *$} \\
\hline & Yes & 53.4 & 46.6 & 431 & \\
\hline \multirow{2}{*}{$\begin{array}{l}\text { Visited health facilities } \\
\text { in the last } 12 \text { months }\end{array}$} & No & 50.7 & 49.3 & 353 & \multirow[t]{2}{*}{$6.457^{*}$} \\
\hline & Yes & 43.7 & 56.9 & 1203 & \\
\hline \multirow{2}{*}{$\begin{array}{l}\text { Information on family } \\
\text { planning received from } \\
\text { health facility }\end{array}$} & No & 42.3 & 57.7 & 1234 & \multirow[t]{2}{*}{$15.375 * * *$} \\
\hline & Yes & 54.5 & 45.5 & 323 & \\
\hline \multirow[t]{3}{*}{ Women's education } & No education & 46.4 & 53.6 & 646 & \multirow[t]{3}{*}{$13.443 * * *$} \\
\hline & Class 1-9 & 47.5 & 52.5 & 625 & \\
\hline & SLC and above & 35.1 & 64.9 & 285 & \\
\hline \multirow{3}{*}{ Husband's education } & No education & 47.9 & 52.1 & 305 & \multirow{3}{*}{3.468} \\
\hline & Class 1-9 & 45.6 & 54.4 & 777 & \\
\hline & SLC and above & 41.5 & 58.5 & 475 & \\
\hline \multirow{3}{*}{$\begin{array}{l}\text { Age of mother at the } \\
\text { birth of last child }\end{array}$} & $<20$ & 46.8 & 53.2 & 222 & \multirow[t]{3}{*}{$15.962 * * *$} \\
\hline & $20-34$ & 42.9 & 57.1 & 1227 & \\
\hline & 35 and above & 62.6 & 37.4 & 107 & \\
\hline \multirow{2}{*}{$\begin{array}{l}\text { Talked about family } \\
\text { planning at PNC visit }\end{array}$} & No & 45.5 & 54.5 & 1403 & \multirow[t]{2}{*}{2.665} \\
\hline & Yes & 38.6 & 61.4 & 153 & \\
\hline \multirow[t]{2}{*}{ Delivery place } & $\begin{array}{l}\text { Not at health } \\
\text { facility }\end{array}$ & 49.1 & 50.9 & 943 & \multirow[t]{2}{*}{$17.933 * * *$} \\
\hline & At health facility & 38.2 & 61.8 & 613 & \\
\hline \multirow[t]{3}{*}{ ANC visit } & No care & 52.5 & 47.5 & 183 & \multirow[t]{3}{*}{$6.620^{*}$} \\
\hline & Moderate care & 45.2 & 54.8 & 823 & \\
\hline & Higher care & 41.6 & 58.4 & 550 & \\
\hline Total & & 44.8 & 55.2 & 1556 & \\
\hline
\end{tabular}

(* indicates $p<0.05, * *$ indicates $p<0.01$ and $* * *$ indicates $p<0.001$ ) 
There is marked difference in use of post-partum contraceptives between the women with and without information about such services. A marginal difference does not exist with both husband and women's education level-No education and little education. But, woman with higher level of education is a significant factor to influence the practice of contraceptive use against the husband's education. Though most of the births are concentrated with the women of age $20-34$, highest proportion $(57 \%)$ of the women with this category have started using contraceptives within 12 months of childbirth. However, slightly more than one third of the women of age 35 years and above used contraceptive within 12 months of the last delivery. Although reasons associated with low user rate are largely unknown, it may indicate possibility of reproductive morbidity and unintended birth. Regarding maternal health components, 58 percent of women with high level of ANC and about 62 percent of women who had delivery care at health facility initiated FP use within a year of the last delivery (Table 2). It gives a window of hope that delivery at health facility predicts the possibility of initiating contraceptive use within a year of delivery.

\section{Results from logistic regression}

Seven different models are constructed to examine the association of maternal health care components on timing of postpartum family planning use. ANCis a single variable included in Modell. It reveals that women receiving higher ANC care is $1.59(\mathrm{p}<0.001)$ times more likely to initiate using contraceptives within 12 months of most recent birth compared women with no care. The second model includes delivery care to predict role in early use of family planning. The result shows a significant higher impact on initiating use of contraceptive within 12 months of last birth for those delivering at health facilities $(\mathrm{OR}=1.592, \mathrm{p}<0.001)$ compared to women who did not delivery at health institution. Here, the gross effects of both ANC and delivery care are no more different.

Model 3 is the combination of both antenatal care and delivery care variables. It reveals that woman giving birth to a child at health facility are more likely $(\mathrm{OR}=1.530, \mathrm{p}<0.001)$ to initiate family planning use within 12 months of delivery compared to those who did not attend at health facility. The influence of antenatal care is offset by delivery care at health facilities for initiating the use of family planning within 12 months of delivery. It may be because recent information would have impact on decision.

Some contextual variables are added in Model 4. Among those variables, only variables such as interaction with family planning workers, approach to health facility and information available from health facilities show significant impact on use of contraceptive within 12 months of the last delivery. For example, women who were visited by family planning workers in the last 12 months were less likely $(\mathrm{OR}=0.73, \mathrm{p}<0.001)$ to initiate contraceptives than their counterpart who were not visited by family planning workers. This result is against assumption but reasons may be because of the low quality of information or they might have decided for next child. But a positive note to observe that the possibility of initiating contraceptives within 12 months of delivery is significantly higher among women visiting health facilities for any health reasons $(\mathrm{OR}=1.5, \mathrm{p}<0.001)$ than those who did not do so. Another important thing to consider from the same model is that those who received information on family planning method from health facility, the chance of initiating the contraceptives within 12 months of delivery declinesby 0.6 times significantly $(\mathrm{OR}=0.589, \mathrm{p}<0.001)$ than those who do belong to that category. Reasons for this discrepancy needs careful analysis but the evidence provide rooms to examine the quality of information and intention of visiting health facilities.

Model 5 adds antenatal care over the Model 4.Results are insignificant for antenatal care but the influence of variables in Model 4 remains more or less the same. This may be because antenatal care is a composite care which covers many other aspects of maternal health and the impact may be seen from specific components of maternal health care. However, the importance of antenatal care is nevertheless less for improving maternal health. 
Maternal Health Care Service Utilization and Its Role in Postpartum Family Planning Use in Nepal

Table 3: Odds ratio of initiating FP use within 12 months of delivery by women's characteristics, Nepal, 2011

\begin{tabular}{|c|c|c|c|c|c|c|c|c|}
\hline Variables & Response & Model 1 & Model 2 & Model 3 & Model 4 & Model 5 & Model 6 & Model 7 \\
\hline \multirow{2}{*}{ Heard family planning on radio in the last few months } & $\mathrm{No}$ & & & & & & & \\
\hline & Yes & & & & 0.853 & 0.855 & 0.863 & 0.861 \\
\hline \multirow[t]{2}{*}{ Heard family planning on TV in the last few months } & $\mathrm{No} \AA$ & & & & & & & \\
\hline & Yes & & & & 1.059 & 1.043 & 0.998 & 0.997 \\
\hline \multirow{2}{*}{$\begin{array}{l}\text { Heard family planning in newspaper/magazine in last few } \\
\text { months }\end{array}$} & $\mathrm{No} \AA$ & & & & & & & \\
\hline & Yes & & & & 1.107 & 1.102 & 1.096 & 1.101 \\
\hline \multirow[t]{2}{*}{ Visited by family planning worker in the last 12 months } & $\mathrm{No} \AA$ & & & & & & & \\
\hline & Yes & & & & $0.725 * * *$ & $0.724 * * *$ & $0.743^{*}$ & $0.742 *$ \\
\hline \multirow[t]{2}{*}{ Visited health facility in the last 12 months } & $\mathrm{No} \AA$ & & & & & & & \\
\hline & Yes & & & & $1.508 * * *$ & $1.482 * * *$ & $1.466 * * *$ & $1.449 * * *$ \\
\hline \multirow{2}{*}{$\begin{array}{l}\text { Information on family planning received during health facility } \\
\text { visit }\end{array}$} & $\mathrm{No} \AA$ & & & & & & & \\
\hline & Yes & & & & $0.589 * * *$ & $0.585 * * *$ & $0.599 * * *$ & $0.595 * * *$ \\
\hline \multirow[t]{3}{*}{ Women's education } & No education ${ }^{\circledR}$ & & & & & & & \\
\hline & Class 1-9 & & & & 0.912 & 0.898 & 0.861 & 0.856 \\
\hline & SLC and above & & & & 1.289 & 1.264 & 1.134 & 1.139 \\
\hline \multirow[t]{3}{*}{ Husband's education } & No education ${ }^{\circledR}$ & & & & & & & \\
\hline & Class 1-9 & & & & 1.049 & 1.052 & 1.033 & 1.043 \\
\hline & SLC and above & & & & 1.039 & 1.032 & 1.004 & 1.012 \\
\hline \multirow[t]{3}{*}{ Age of mother at the birth of most recent child } & Less than $20 \AA$ & & & & & & & \\
\hline & $20-34$ & & & & 1.091 & 1.097 & 1.121 & 1.127 \\
\hline & 35 above & & & & 0.690 & 0.707 & 0.711 & 0.725 \\
\hline \multirow[t]{2}{*}{ Talked about family planning at PNC } & $\mathrm{No} \circledast$ & & & & & & & \\
\hline & Yes & & & & 1.138 & 1.124 & 1.012 & 1.011 \\
\hline \multirow[t]{3}{*}{ Antenatal care } & No care $\mathbb{R}$ & & & & & & & \\
\hline & Moderate care & 1.321 & & 1.210 & & 1.24 & & 1.197 \\
\hline & High care & $1.592 * * *$ & & 1.23 & & 1.23 & & 1.117 \\
\hline \multirow[t]{2}{*}{ Delivery place } & Not at health facility ${ }^{\circledR}$ & & & & & & & \\
\hline & At health facility & & $1.592 * * *$ & $1.530 * * *$ & & & $1.384 * *$ & $1.382 *$ \\
\hline -2LogLikelihood & & 2193.65 & 2182.74 & 2179.89 & 2137.24 & 2139.34 & 2136.01 & 2133.159 \\
\hline
\end{tabular}

(* indicates $p<0.05, * *$ indicates $p<0.01$ and $* * *$ indicates $p<0.001$ ), ${ }^{\circledR}=$ reference category

Journal of Management and Development Studies (26) 
Model 6 is an improvement over Model 4 by adding delivery care. The net effect of initiating contraceptives within 12 months of last delivery is higher $(\mathrm{OR}=1.38, \mathrm{p}<0.01)$ among the women who attended health facility for delivery against non-attending women. However, the net effect of delivery care has declined than the gross effects observed in Model 2 by some 13 percent as the impact is disintegrated with other variables. Another important thing to conclude from Model 6 is that the net effects of variables included in Model 4 remain unchanged. It helps to conclude that delivery care at health facilities seems to be very influential for the contraceptive use within 12 months of the last delivery.

The final Model 7 includes all variables under study. No significant change is observed than Model 6. The net effect of delivery care remains same as in Model 6 and the variables which have seen significant effects in model 4 have the same net effects in the Model 7. From the last two models, it can be concluded that the delivery at health facility is most important component to determine the use of contraceptives within 12 months of the last delivery.

\section{Discussion and Conclusions}

The contraceptive prevalence rate has not been improved significantly since 2006 in Nepal. Though the family planning services were incorporated in the maternal and child health programme since a long time, the influence of maternal health care on contraceptive use has not increased significantly. Similarly, the stagnation in family planning use in Nepal is attributed to male migration from the family for employment (Khanal et.al, 2013). The different models used in this paper show that delivery care has a significant effect on post-partum contraceptive practices. Delivery care at health facility can be considered as the most important opportunity to provide necessary information to the couples on family planning use. Counselling on family planning in presence of both husband and wife could be seen rewarding. Nepal has received success in increasing the institutional delivery and which is supposed to be instrumental to achieve the millennium development Goal 5.It is proving to be rewarding for improving overall maternal health.

The role of delivery care in using contraceptive within 12 months after last delivery seems to be very influential in Nepal. Currently, 6 out of 10 pregnant women give birth out of health facility. Therefore, to make resume the use of contraceptives within 12 months following delivery, emphasis should be given in the institutional delivery. Besides, proper institutional arrangement for family planning should be further strengthened to reach all women of reproductive age irrespective of the place of delivery. For this, Even FCHVs can be capacitated as a new actor for counselling on FP targeting all women irrespective of their prior knowledge or given birth at health facility. This could be possible through simple directives from Department of Health Services because currently the Government of Nepal provides at least three types of contraception throughout the year across the country.

McGuire (1981) explains that the tendency to visit health institutions provides opportunity to supply the information on services available in the health institutions. However, in Nepal where socio-economic condition is still far behind compared to developed countries, and the health targets have not been met satisfactorily, integration of family planning with maternal and child health programme has been indispensable. Despite the poor standard of health facilities, there is increasing pressure in health services. It may limit opportunity of interaction with clients including family planning. It should be made mandatory to provide post-partum family planning information in the presence of husband or their closed relatives which would promote contraceptive use following childbirth. Delivery at health institutions should be emphasized as it may be instrumental to improve post-partum timely initiation of family planning. A follow-up mechanism to record status of family planning use would help to adopt a proper counselling method. Health professionals should be trained to provide sufficient information to clients. In a nutshell, emphasis on family planning programme by 
the government together with maternity care would promote use of family planning; reduce the chances of unwanted/unintended birth, provide opportunities to realize reproductive rights, contribute in achieving replacement level fertility and maintain good health for both mother and the baby.

\section{References}

Ahmed, S., \& Mosley, W. H. (2002). Simultaneity in the use of maternal child health care and contraceptives: Evidence from developing countries. Demography, 39 (1): 75-93.

Department of Health Services [DoHS]. (2005). Operational guidelines on incentives for safe delivery services 2005 [2062]. Kathmandu: Department of Health Services, Family Health Division, Ministry of Health and Population.

Department of Health Services [DoHS]. (2008). Operational guidelines on safe motherhood programme 2008 [2065]. Kathmandu: Department of Health Services, Family Health Division, Ministry of Health and Population.

Department of Health Services [DoHS]. (2014). Annual Report (2012/13). Kathmandu: Department of Health Services, Family Health Division, Ministry of Health and Population.

Do, M.\& Hotchkiss, D. (2011). Relationships between maternal health care and postpartum modern contraceptive use in Kenya and Zambia. MEASURE Evaluation Series-WP-11120.Retrieved 12 June 2015 from http://www.cpc.unc.edu/measure/prh

Ram, F. \& Singh, A.(2006). Is antenatal care effective in improving maternal health in rural Uttar Pradesh? Evidence from a District level household survey. Journal of Biosocial Science, 38:433-448.

Hotchkiss, DR., Magnani, J., Rous, JJ., Azelmat, M., Mroz, TA.\& Heikel. J. (1999). The effects of maternal-child health service utilization on subsequent contraceptive use in Morocco. Journal of Biosocial Science 31(2): 145-165.

Hotchkiss, D. R, Rous, JJ., Seiber, EE.,\& Berruti, AA. (2005). Is maternal and child health services use a casual gateway to subsequent contraceptive use? A multi country study. Population Research and Policy Review 24(6):543-571.

Khanal MN., Shrestha, DR., Panta, PD., \&Mehta S. (2013). Impact of male migration on contraceptive use, unmet need and fertility in Nepal. Further analysis of the 2011 Nepal demographic and health survey. Calverton, Maryland, USA: Ministry of Health and Population, New ERA, and ICF International.

McGuire, W.J. (1981). The theoretical foundations of campaigns. Public Communication Campaigns ( eds) Rice. W. \& Paisley, W. pp:41-70. Beverly Hills, CA: Sage Publications.

Ministry of Health [Nepal], New ERA, \& ORC Macro. (2002). Nepal demographic and health survey 2001.Calverton, Maryland, USA: Family Health Division, Ministry of Health; New ERA; and ORC Macro.

Ministry of Health and Population (MOHP)[Nepal], New ERA, \&ICF International Inc. (2012).Nepal demographic and health survey 2011. Kathmandu, Nepal: Ministry of Health and Population, New ERA and ICF International, Calverton, Maryland, USA.

Ministry of Information and Communication [MOIC]. (2012).List of licenced and in broadcasting FM radios in Nepal. Retrieved on May 21, 2014 from http://www.moic.gov.np/pdf/fm-regular2069-10-25.pdf

National Planning Commission [NPC]. (1963).The first plan (1963-68). Kathmandu: National Planning Commission.

Patel, T. (2012).Medical pluralism in contemporary India. New Delhi: Orient Blackswan Pvt Ltd. 
Maternal Health Care Service Utilization and Its Role in Postpartum Family Planning Use in Nepal

Raghupathy, S. (1997). Unwanted pregnancies and preventive health care use in Thailand. Population Research and Policy Review 16(6):579-595.

Yahaya, M. K. (2002). Analysis of women's reproductive health situation in Bida Emirale of Niger State, Nigeria. African Journal of Reproductive Health 6(1): 50-64.

Zerai, A. \& Tsui, A.O. (2001). The relationship between prenatal and subsequent modern contraceptive use in Bolivia, Egypt and Thailand. African Journal of Reproductive Health 5(2):68-82. 